\title{
CULTURA E QUALIDADE NA EDUCAÇÃO FÍSICA A PARTIR DE INTERLOCUTORES URUGUAIOS
}

\author{
Eliane Regina Crestani Tortola' \\ Ellen Grace Pinheiro? \\ Carlos Herold Junior \\ Vânia de Fátima Matias de Souza ${ }^{4}$ \\ Larissa Michelle Lara ${ }^{5}$
}

\section{RESUMO}

Este texto discute como a cultura e a qualidade na educação são tematizados na educação física, no contexto uruguaio, tomando como base orientadora incursões por referenciais teóricos que atentem para essa problemática e colaborações de pesquisadores da área vinculados à Universidad de la República do Uruguay. As análises indicam que o tema cultura é secundário em relação às tradicionais abordagens da educação física uruguaia e que a qualidade da educação/educação física, apesar de complexa e orientada por interesses neoliberais, pode ser entendida como forma de acesso ao tratamento atualizado e crítico do conhecimento pelos sujeitos em formação.

Palavras-chave: Educação Física. Cultura. Qualidade. Uruguai.

1 Doutoranda em Educação Física. Professora da Universidade Estadual de Maringá (UEM) e da Faculdade Metropolitana de Maringá (UNIFAMMA). Maringá/Paraná, Brasil. E-mail: elitortola@gmail.com

2 Mestranda em Educação Física. Professora da Secretaria de Educação do Paraná (SEED/PR). Marialva/Paraná, Brasil. E-mail: ellen_gr@yahoo.com.br

3 Doutor em Educação. Professor da Universidade Estadual de Maringá (UEM). Maringá/Paraná, Brasil. E-mail: carlosherold@hotmail.com

4 Doutora em Educação. Professora da Universidade Estadual de Maringá (UEM). Maringá/Paraná, Brasil. E-mail:vfmatias@gmail.com

5 Doutora em Educação. Professora da Universidade Estadual de Maringá (UEM). Maringá/Paraná, Brasil. E-mail: laramlara@hotmail.com 


\title{
CULTURE AND QUALITY IN PHYSICAL EDUCATION FROM URUGUAYAN INTERLOCUTORS
}

\begin{abstract}
This article discusses how culture and quality education are considered in physical education in the Uruguayan context. The text is grounded in incursions through theoretical frameworks that give attention to this problem, as well as in assertions made by researchers in the area who work in the University of the Republic of Uruguay. The analyzes indicates that the questions related to culture are ancillary if compared to traditional approaches carried out by Uruguayan physical education. When it comes to the theme of quality in education / physical education, although complex and guided by neoliberal interests, it can be assumed as an updated and critical approach to foster access to knowledge by undergraduate subjects during their formation process.
\end{abstract}

Keywords: Physical Education. Culture. Quality. Uruguay.

\section{CULTURA Y CALIDAD DE LA EDUCACIÓN FÍSICA DESDE INVESTIGADORES URUGUAYOS}

\section{RESUMEN}

El texto presenta una discusión respecto de cómo la cultura y calidad en educación son tematizados en la Educación Física de Uruguay, tomando como guía las referencias teóricas consultadas y las colaboraciones de investigadores en el área de la Universidad de la República de Uruguay. Los análisis y resultados indican que lo referido a la cultura se ve replegado a un segundo plano en relación a los enfoques tradicionales de la Educación Física de Uruguay y la calidad de la Educación/Educación Física, a pesar de su complejidad y estar guiada por intereses neoliberales, es posible entenderla como un medio de acceso al tratamiento del conocimiento actualizado y crítico por parte de los sujetos en formación.

Palabras clave: Educación Física. Cultura. Calidad. Uruguay. 


\section{INTRODUÇÃO}

A busca pela compreensão de campos temáticos afetos à educação física tem se configurado em esforço para problematizar questões identitárias da área e da produção de conhecimento, as quais envolvem processos de organização dos setores acadêmico e profissional. Nessa perspectiva, fronteiras passam a ser exploradas e modos de percepção do "outro" transcendem realidades locais rumo a aprendizados oportunizados pela imersão em contextos distintos, como aqueles configurados pela educação física em países latino-americanos, o que sugere modos peculiares de intervir na nossa própria realidade. Isso requer a saída da zona de conforto e estabilidade para a busca de deslocamentos que nos possibilitem olhar para realidades distintas da nossa de modo a reconhecermos nelas modos próprios de organização e de conhecimento que se constituem como campos de diálogo e aprendizado.

Partindo desse entendimento é que objetivamos entender como a relação entre cultura e educação física é desenvolvida em contextos diferentes do nosso, questionando se é possível falar em qualidade na educação/educação física. Neste texto, essa intenção concretiza-se por meio da investigação junto à educação física a partir de interlocutores uruguaios. Em especial, o enfoque centrou-se na análise das questões da cultura e da qualidade na educação/educação física a partir de incursões teóricas e colaboração de pesquisadores via instrumento on-line e reunião institucional. Nossa expectativa é de que esses resultados possam agregar a questões epistêmicas desenvolvidas na área, constituindo-se como alicerces que sustentem um pensamento crítico e interventor. Nessa direção, as questões epistêmicas que embasam este estudo poderão ser incrementadas por aquilo que, de imediato, pretendemos: refletir sobre diferentes entendimentos no que tange à cultura na produção de conhecimento em educação física no Uruguai, avaliando-os como relevantes não apenas na delimitação de objetos de investigação dos pesquisadores da área, mas também no trato da temática nas aulas de educação física escolar.

Estudos desenvolvidos por Silva e Bedoya (2015) têm contribuído para pensar as particularidades da formação inicial em Educação Física na América Latina e dos avanços e limites encontrados em cada realidade a partir de como pesquisadores convidados fazem a leitura desse tema em seus países, o que agrega às nossas investigações. Reflexões acerca da tematização da cultura na produção de conhecimento da educação física colombiana voltada para a escola e do debate em torno da qualidade na educação/educação física (SILVA et.al, 2015) refinam nosso olhar acerca de outras realidades investigadas e suas distintas configurações, a exemplo da educação física uruguaia que ora nos propusemos a desenvolver nesse texto pelo viés da cultura e da qualidade na educação.

Integra essa motivação inicial o estudo desenvolvido por Lopes em relação ao papel ocupado pela cultura na educação física, no Brasil, ao apontar que "a ampliação do número de publicações que discutem a cultura, sob várias perspectivas, tem gerado certo consenso entre teóricos que pesquisam esse campo no que diz respeito à importância que essa temática passou a exercer nas mais diversas esferas sociais" (LOPES, 2013, p. 110). A autora destaca, ainda, a associação da palavra cultura a termos como movimento, corporal, 
corporal de movimento, movimento humano, não como mera junção, mas como forma de discorrer acerca do objeto da própria educação física a partir de diferentes teorias que subsidiam a área, discutindo acerca de como o conceito de cultura torna-se central na produção de conhecimento da educação física brasileira. Tal investigação deflagrou-se como motivação à necessidade de entender como a relação entre cultura e educação física era desenhada em realidades latino-americanas, para além do Brasil, o que se deu por meio de um amplo projeto investigativo iniciado ao final de 2011, envolvendo oito países. O Uruguai é, portanto, um dos países investigados a partir da colaboração de pesquisadores ligados à formação no Ensino Superior, cujos resultados são aqui apresentados e discutidos.

No que tange à concepção de qualidade na educação, partimos do pressuposto, com base em Goergen (2010, p. 895), de que ela é "[...] complexa e abrangente conforme as circunstâncias, os fatores intra e extrainstitucionais, as dimensões socioeconômicas, a disponibilidade de recursos, etc." e que o entendimento desse termo e sua apropriação no âmbito educativo "deve ser resultado de um amplo debate que leve em consideração o contexto, o momento histórico, as condições sociais e culturais que envolvem cada instituição". Nessa direção, a qualidade na educação/educação física a que nos referimos nesta pesquisa considera as diferenças constitutivas da realidade abordada, assim como se pauta em orientações de critérios humanísticos (e não mercadológicos) para pensar aquilo que de melhor a área pode oferecer em termos de formação.

Como ponto de partida do estudo, consideramos importante contar com o aporte de documentos orientadores da legislação do país para a educação e a educação física de modo a compreendermos questões atinentes às políticas educacionais vigentes. Além disso, realizamos o mapeamento das instituições uruguaias que ofereciam o curso superior de educação física a partir dos sites vinculados ao Ministério da Educação ${ }^{6}$ no Uruguai, sendo encontrados o Instituto Superior de Educação Física (ISEF) - Universidad de la República $(\text { UdelaR })^{7}$ - única universidade pública do Uruguai - e o Instituto Universitario Asociación Cristiana de Jóvenes (IUACJ) ${ }^{8}$. Entretanto, por entendermos o papel significativo das instituições públicas na formação universitária, pautadas nas determinações e orientações do Estado, e por adotarmos como critério a seleção de pesquisadores vinculados a universidades com esse perfil, convidamos docentes ligados à Universidad de la República para colaborarem com essa pesquisa.

O convite foi feito a três professores a partir da interlocução que desenvolvem com o campo sociocultural na educação física, com abordagens em torno de políticas educacionais, formação de professores, educação física escolar e educação do corpo, a exemplo de Dogliotti (2013a, 2013b, 2012a, 2012b, 2012c, 2009), Rodríguez Giménez

6 Informações disponíveis em: <http://www.mec.gub.uy/>. Acesso em: 19 jul. 2016.

7 O Instituto Superior de Educação Física (ISEF) - Universidad de la República (UdelaR/ Uruguay) - foi fundado em 1833 e o curso de educação física, implantado em 1939, com duração de quatro anos. Informações complementares são encontradas no site oficial da instituição, disponível em: < http://www.isef.edu.uy/> . Acesso em: 19 jul. 2016.

8 O Instituto Universitário Associação Cristã de Moços, fundado em setembro de 2000, oferece curso de licenciatura em educação física, recreação e esporte, com duração de quatro anos. Informações complementares podem ser encontradas no site oficial da instituição, disponível em: < http://www.iuacj.edu.uy/index.php/carreras/ licenciatura_educacion_fisica >. Acesso em: 19 jul. 2016. 
(2013, 2010, 2009, 2007), Seré Quintero (2011) e Seré Quintero, Fernández Vaz (2015). Soma-se a essa produção a participação dos docentes no "Grupo Políticas de Investigação e Políticas Educativas na educação física" (GPEPI), vinculado ao ISEF/UdelaR ${ }^{9}$.

Nesse processo, percebemos que a produção do conhecimento dos professores selecionados voltava-se, de alguma forma, para os eixos temáticos desse estudo, o que se configurava como espaço profícuo para a coleta de dados aqui empreendida. A partir daí, contatamos os seguintes pesquisadores via e-mail, para participarem da pesquisa: Raumar Rodriguéz Giménez ${ }^{10}$, Paola Dogliotti ${ }^{11}$ e Cecília Seré Quintero ${ }^{12}$, sendo representados, respectivamente, nesse artigo, por P1UY (2015a, 2015b), P2UY(2015) e P3UY(2015), ou seja, pesquisadores 1, 2 e 3/Uruguai, respeitando-se a ordem do recebimento dos dados do questionário. O intuito é demarcar as colaborações advindas do instrumento de coleta daquelas decorrentes das produções teóricas a eles atinentes. Tais pesquisadores prontamente se dispuseram a colaborar, anuindo tornar públicos seus nomes ${ }^{13}$ e dados alusivos à coleta ${ }^{14}$.

9 Embora a escolha de pesquisadores vinculados ao mesmo grupo não tenha sido um critério intencional da pesquisa, entendemos (a posteriori) que esse fato poderia contribuir com a coleta de informações dado o importante papel de grupos de pesquisa nas universidades no tocante a reflexão crítica e democratização do conhecimento. A quantidade de três pesquisadores foi um critério previamente estabelecido para o projeto desenvolvido com países da América Latina, a exemplo do Uruguai, no sentido de valorizar a dimensão qualitativa do estudo a partir da colaboração enviada por meio do instrumento de coleta. O Grupo Políticas Educativas y Políticas de Investigación do Instituto Superior de Educación Física - Universidad de la República (Montevideo-Uruguay) tem como objetivo contribuir para o desenvolvimento do conhecimento específico para o campo da educação física e para a elucidação das relações teórico-práticas entre política educacional e política de investigação no campo. Informações acerca do GPEPI são encontradas no site do grupo, disponível em: < http://gpepi.blogspot.com.br/p/participantes-del-gpepi-en-el-ano-2009.html >. Acesso em: 19 jul. 2016.

10 Doutor em Ciências Humanas (Programa de Pós-Graduação Interdisciplinar em Ciências Humanas, Centro de Filosofia e Ciências Humanas/ UFSC). Mestre em Ensino Universitário (Maestría en Enseñanza Universitaria - Universidad de La República, 2012). Licenciado em Ciências da Educação pela Facultad de Humanidades y Ciencias de la Educación, Universidad de la República. Professor de Educação Física do Instituto Superior de Educación Física (ISEF/UdelaR). Coordenador do Grupo Políticas Educativas y Políticas de Investigación en Educación Física (GPEPI), ISEF-UdelaR. Currículo disponível em: < http://buscatextual.cnpq.br/buscatextual/ visualizacv.do? $\mathrm{id}=\mathrm{K} 4090702 \mathrm{~J} 8>$. Acesso em: 19 jul. 2016.

11 Doutoranda em Educação, à época da coleta, pela Universidad Nacional de La Plata, na Argentina. Mestre em Ensino Universitário pela Universidad de La República, no Uruguai (Facultad de Humanidades y Ciencias de la Educación). Graduada em Educação e Especialista em Currículo e Práticas no contexto escolar pela Facultad Latinoamericana de Ciencias Sociales, na Argentina. Graduada em Ciências da Educação (2002) e em Educação Física (1991) pela Universidad de la República, no Uruguai. Atualmente é docente universitária pela Universidad de la República. Currículo disponível em: < http://buscadores.anii.org.uy/buscador_sni/exportador/ExportarPd $\mathrm{f}$ ?hash = 762af993b01661 be9ca47474099f23f1 > . Acesso em: 19 jul. 2016.

12 Doutoranda, à época da coleta, no Programa de Pós-graduação Interdisciplinar em Ciências Humanas (PPGICH/ CFH/UFSC). Mestre em Educação pelo Programa de Pós-graduação em Educação pela Universidade Federal de Santa Catarina (PPGE/CED/UFSC). Graduada em Educação Física pela Universidad de la Republica (2011). Atualmente é docente universitária junto à Universidad de La República. Currículo disponível em: <http:// buscatextual.cnpq.br/buscatextual/visualizacv.do?id=K4362198P5>. Acesso em: 19 jul. 2016

13 Os pesquisadores participantes desse estudo foram consultados acerca da referência dada às suas obras durante essa pesquisa, os quais orientaram que fossem citados como "Rodríguez Giménez", "Dogliotti" e "Seré Quintero", conforme visualizado em seus respectivos currículos.

14 Se, por um lado, a participação de três professores vinculados à mesma instituição e grupo de pesquisa pode indicar limitações à forma de olhar para a problemática investigativa, sobretudo por compartilharem a mesma realidade, tende a acenar para como cada pesquisador constrói a sua subjetividade em meio a esse coletivo e 
A participação dos professores/pesquisadores deu-se por meio de questionário on-line com questões abertas, encaminhado por e-mail, juntamente com o Termo de Consentimento Livre e Esclarecido, envolvendo as seguintes problemáticas: a) como o tema "cultura" é abordado na produção do conhecimento em educação física no Uruguai?; b) conceitos como cultura física, cultura corporal, cultura de movimento ou outro que traga a palavra cultura integram a produção de conhecimento da educação fisica?; c) o tema da cultura é desenvolvido em aulas de educação física?; se sim, quais são os principais marcos teóricos que tratam a cultura na sua relação com a educação física escolar?; d) como se dá a discussão acerca da qualidade na educação/educação física no Uruguai?; e) é possível afirmar a existência de qualidade na educação física escolar em seu país?.

O questionário foi estruturado pelo Grupo de Pesquisa Corpo, Cultura e Ludicidade (GPCCL-DEF/UEM), em consonância com as finalidades do projeto. Dados puderam ser coletados, ainda, pessoalmente, por meio da participação do professor Raumar Rodríguez Giménez em reunião institucional ocorrida, em 2015, no Departamento de Educação Física da Universidade Estadual de Maringá (DEF/UEM), por ocasião do VI Congresso Internacional de Pedagogia do Esporte-CIPE. A análise deu-se a partir das categorias temáticas definidas previamente, quais sejam, cultura na educação física e qualidade na educação/educação física, as quais orientaram nossas buscas em documentos educacionais do país, em literatura específica acerca do tema abordado e em artigos acadêmico-científicos escritos pelos professores/pesquisadores que colaboraram com essa investigação.

No intuito de apresentar os dados de pesquisa acerca da relação entre cultura e educação física, bem como da qualidade na educação/educação física a partir de incursões teóricas e, notadamente, por meio da colaboração de pesquisadores no Uruguai, o presente estudo organiza-se em duas seções: a) Dimensões da educação física e cultura na realidade uruguaia, em que são trazidos dados sobre a educação física, o conceito de cultura na produção de conhecimento, o trato da cultura nas aulas de educação física escolar e os principais marcos teóricos que tratam da cultura na educação física escolar, segundo os pesquisadores; b) Reflexões acerca da qualidade na educação/educação física no Uruguai, em que o tema da qualidade na educação/educação física é fomentado a partir da leitura dos colaboradores.

\section{DIMENSÕES DA EDUCAÇÃO FÍSICA E CULTURA NA REALIDADE DO URUGUAI}

O processo de constituição educativa, no Uruguai, deu-se motivado pelo questionamento aos pactos coloniais, com orientações das ideias de João Pedro Varela (1845-1879) ao assumir, segundo Demarchi e Rodrigues (2010, p. 12), "[...] a tarefa de estabelecer um sistema comum de educação", deixando, como informam, uma herança cultural para o século XX, qual seja, os conceitos de ensino público gratuito e igualitário, a secularização,

como apreende dado fenômeno investigativo, como observado nas respostas que trazem às questões que lhes são postas nessa pesquisa. 
o método racional e a independência da educação. Tal herança foi sentida até meados da década de 1950, com a expansão de matrículas sem os necessários aportes orçamentários e com o impacto na infraestrutura e na qualidade e quantidade de profissionais qualificados para o ensino (URUGUAI, 2005). A partir de 1990, ocorreram reformas educacionais que vieram impactar a educação uruguaia (DOGLIOTTI, 2009, p. 23, tradução nossa).

Em 12 de dezembro de 2008, a educação na República Oriental do Uruguai passa a ser regida pela Lei $n^{\circ} .18 .437$, publicada em 16 de janeiro de 2009, que regula os objetivos, os princípios e as diretrizes da educação, com interesse pela promoção e realização do direito à educação como um direito humano fundamental. Essa lei foi concebida com o intuito de se construir um sistema nacional de educação que delega ao Estado "garantir e promover a educação de qualidade para todos os seus habitantes, ao longo da vida, facilitando a continuidade educativa" (URUGUAI, 2009, p.1, tradução nossa).

A educação física escolar efetivou-se, no país, em 27 de novembro de 2007, por meio do artigo único da Lei $\mathrm{n}^{\circ}$. $18.213^{15}$ (DOGLIOTTI, 2012a), após significativas mudanças ${ }^{16}$ ocorridas em 2005, nas políticas relacionadas à educação pública uruguaia, conforme explicam Rodríguez et al. (2009). A disciplina educação física tornou-se obrigatória, defendida pelo Presidente da República - Dr. Tabaré Vázquez - por meio do Projeto de obrigatoriedade da educação física escolar. A iniciativa presidencial foi recebida pela sociedade e aprovada por unanimidade no parlamento uruguaio (DOGLIOTTI, 2012a).

Já a formação superior em educação física, no Uruguai, ficou a cargo da Universidad de la República ${ }^{17}$, no ano de 2006. Antes disso, afirma Dogliotti (2013a), a preparação de professores de educação física, no país, foi orientada pelos ideais de Julio J. Rodriguez que, em 1921, apresentou o primeiro projeto à Comissão Nacional de Educação Física (CNEF), sendo ele o Diretor Técnico. O projeto previa a formação em um ano e, após, em 1939, o Curso de Formação de Professores de educação física passa a ter três anos de duração. A autora ainda salienta que, para desenvolver e apoiar o seu projeto, Julio J. Rodriguez baseou-se no modelo estadunidense orientado pela Associação Cristã de Moços (YMCA), o que veio a nortear ações no trato com a educação física no país.

A educação física, no Uruguai, é disciplina obrigatória na escola e campo de formação em nível superior, sendo amparada por modelos advindos das ciências biomédicas. Isso faz com que a interlocução com as ciências humanas e sociais tenha pouco espaço na área. O tema da cultura, que integra disciplinas de cunho humanístico, carece de tematização, asseguram os pesquisadores participantes da pesquisa, o que não aponta, entretanto, para seu desconhecimento. Como informa P2UY (2015, tradução nossa), há predominância do esporte e da atividade física em detrimento da cultura no trato com a educação física, seja nos campos da educação formal ou não-formal no Uruguai. Desde

15 Lei que passa a regulamentar a educação uruguaia a partir de 12 de dezembro de 2008.

16 As mudanças a que se referem os autores dizem respeito aos programas educacionais que passaram a conferir à educação física a responsabilidade na formação corporal dos sujeitos uruguaios.

17 A Universidad de la República (UdelaR) é a única universidade pública do país, conforme assegura Dogliotti (2012c). 
a perspectiva empreendida por Varela, no final do século XIX e início do século XX, a educação física refere-se ao "exercício físico ou ginástica" (DOGLIOTTI, 2012b, p. 3, tradução nossa), o que faz alusão a sua concepção corporal higienista. Tal perspectiva de uma educação física ainda pautada pelo esporte e pela atividade física vincula-se a uma abordagem predominante, mas não hegemônica na forma de se pensar a área no país. Tal entendimento torna-se elucidativo com os apontamentos desenvolvidos por P1UY (2015b)18, o qual, em reunião institucional realizada na Universidade Estadual de Maringá, durante o VI Congresso Internacional de Pedagogia do Esporte, em 2015, discorreu acerca do processo que, segundo ele, culminou com a visualização de outros saberes permeando o campo da educação física no Uruguai, a partir da década de 1990, os quais tiveram a influência da produção de conhecimento brasileira.

Para nós, a questão da produção do conhecimento se coloca de maneira clara e forte só com o ingresso na Universidade, em 2006, porque fora da universidade não era exigência a pesquisa. Aliás, é interessante porque, na verdade, quase por acaso, chega ao Uruguai, na década de 1990, alguns livros do Brasil e depois a gente viu que, claramente, na região, é o país que mais avançou numa leitura crítica da educação física e, para nós, o nome que se destaca é o de Valter Bracht. Acho que o primeiro livro dele que circulou no Uruguai foi "Educação física e aprendizagem social". [...] Isso para dizer que a questão da cultura entrou nas nossas preocupações, não só, obviamente, pelo livro do Valter, naquela época, mas para vários professores do ISEF, a educação física era uma coisa incompleta, [...] então, vários professores começaram a fazer outras formações - Antropologia, Educação, História, Sociologia (P1UY, 2015b19).

O pesquisador deixa registrado o papel da universidade nessa abordagem crítica como local em que pesquisas científicas são empreendidas, bem como a contribuição que a obra20 do pesquisador brasileiro Valter Bracht, mencionada anteriormente, deu para a releitura da educação física no Uruguai. P1UY (2015b) destaca, ainda, a formação complementar buscada por profissionais da educação física em áreas do conhecimento aportadas nas humanidades, a qual contribuiu para ampliar percepções da área que não aquelas atinentes ao seu viés médico-biológico, uma vez que a educação física passou a ser entendida por esses profissionais por orientações não apenas ligadas às dimensões física ou esportiva.

A compreensão dos modos pelos quais o tema da cultura parece ser ainda incipiente na educação física no contexto dos pesquisadores uruguaios pode ser percebida pelas questões levantadas aos próprios docentes, via questionário on-line, quais sejam: a) o conceito de cultura é parte da produção de conhecimento da educação física em seu país?; se sim, como isso ocorre? b) conceitos como cultura física, cultura corporal, cultura do movimento

18 Participação do docente em reunião institucional realizada na Universidade Estadual de Maringá, durante o VI Congresso Internacional de Pedagogia do Esporte, em 2015.

19 Não houve tradução pelo fato do pesquisador ter se pronunciado na Língua Portuguesa.

20 A obra de Valter Bracht mencionada por P1UY é "Educação física e aprendizagem social" (BRACHT, 1992). 
ou outro que traz o tema da cultura integram a produção do conhecimento da educação física em seu país? c) existe um conceito predominante? d) como isso se desenvolve? e) o tema da cultura está presente em aulas de educação física na escola no seu país? f) como essa questão é tratada nas aulas de educação física escolar? g) o que poderia ser o potencial e a limitação da produção do conhecimento em educação física em seu país?

As respostas dos pesquisadores acerca de questões referentes à cultura na produção de conhecimento em educação física no Uruguai indicam que o tema é recente, haja vista que outras formas de apropriação dos saberes que envolvem a área só foram efetivadas a partir da criação do primeiro curso de formação universitária em educação física no país, no ano de 2006. Como observa P3UY (2015, tradução nossa) ${ }^{21}$, o conceito de cultura é "tomado a partir de outras perspectivas disciplinares, produto, em parte, da vinculação dos docentes do Instituto Superior de Educação Física (ISEF) com outras áreas de conhecimento (favorecido pelo início de realização de pós-graduação em áreas vinculadas às ciências sociais e humanas)" e que "[...] no grosso das produções de conhecimento do campo, geralmente é mencionado, mas não aprofundado".

Quanto à utilização dos conceitos de cultura física, cultura corporal e cultura do movimento, algo demarcado na realidade brasileira a partir de referenciais teóricos distintos, como apontam Lara (2016, 2013), Lopes (2013) e Daolio (2004), os três docentes/ pesquisadores afirmam que o termo cultura física é o que predomina, uma vez que

[...] a noção de "cultura física" se registra desde inícios do século XX, em que o impulso modernizador de caráter higienista e eugenista levou à criação da Comissão Nacional de Educação Física, em 1911. Este organismo estatal se encarregou de organizar e favorecer o desenvolvimento da 'cultura física' no país (P3UY, 2015, tradução nossa).

P1UY (2015a) corrobora com P3UY (2015, tradução nossa) ao afirmar que "um dos organismos estatais de ensino médio utiliza a expressão 'cultura física' como eixo fundamental de sua política educativa". Esse entendimento trazido pelo pesquisador é apresentado nos estudos de Dogliotti (2013b) acerca dos postulados de Alejandro Lamas $^{22}$, quando a autora esclarece que "o conceito de corpo ou cultura física está ligado ao conceito de desenvolvimento, uma vez que o corpo é visto como um conjunto de órgãos em desenvolvimento e que permite a prosperidade econômica e o progresso científico" (DOGLIOTTI, 2013b, p. 208, tradução nossa). Daí que o conceito de cultura física acaba se definindo, na realidade uruguaia, a partir de uma "cultura do físico", destituída da interlocução com as humanidades e de uma percepção ampliada do próprio corpo para além de sua fisicalidade.

21 Os pesquisadores, nesse artigo, são identificados pelo seu sobrenome, seguido do ano da realização da entrevista.

22 Alejandro Lamas foi professor de ginástica do início do século XX e dedicou-se à sistematização de um Plano Educacional para a Educação Física, a ser implementado no ensino primário e posto em prática pelos professores das escolas normais (Dogliotti, 2013b). 
Em relação à questão que envolve o trato com o tema cultura nas aulas de educação física escolar, P2UY (2015, tradução nossa) afirma que "uma coisa são as discussões dos temas da cultura corporal dentro da formação dos professores no ISEF e outra muito distinta é ver como isso se traduz em uma aula de educação física, seja na educação primária, pré-escolares ou secundária", o que aponta para as dificuldades em relação ao conhecimento adquirido teoricamente e a aplicação prática desse conhecimento. Entretanto, P2UY (2015, tradução nossa) explica que "cada vez há maior consciência por parte dos docentes que a educação física é uma construção social e histórica e, portanto, também é uma expressão da cultura". A docente relata que existem esforços em recuperar diversas formas de culturas e expressões do corpo, algo que aparece gradativamente como alternativo e não como central, predominando, ainda, o aspecto competitivo e "um trabalho sobre o corpo mais relacionado ao orgânico" (P2UY, 2015, tradução nossa).

No caminho que leva à crítica aos modos tradicionais de sistematização de uma educação física focada na atividade física e no esporte está a percepção diferenciada do próprio corpo, uma vez que "[...] as últimas gerações de profissionais de EF têm incorporado a crítica cultural da educação do corpo", afirma P1UY (2015a, tradução nossa), quebrando a [...] "hegemonia biomédica que predominou no campo da EF do Uruguai desde o fim do século XIX" (tradução nossa). Assim, entende que, ao pensarem, por exemplo, no futebol como fenômeno cultural, não são poucos os professores de educação física que rompem com a visão orgânica e anatomofisiológica do corpo. Segundo o pesquisador, que endossa essa discussão em seus estudos envolvendo as políticas educacionais para a educação física em seu país, é necessário pensar que

[...] a higiene não é só do corpo, é, em última análise social e cultural, econômica e até política. Por isso, tem sido importante inverter a afirmação de que na escola o corpo não tem lugar para dizer que o centro da escola é, em certo sentido, o corpo. Ele é o ponto no qual se cruzam todas as linhas da governamentalidade (RODRÍGUEZ GIMÉNEZ, 2013, p. 111, tradução nossa).

Ao serem questionados acerca dos marcos teóricos que fomentam a discussão da cultura na educação física escolar uruguaia, os participantes da pesquisa mencionam, em geral, a presença de autores brasileiros, espanhóis, argentinos, alemães, ingleses e franceses. São lembrados por P1UY (2015a) e P3UY (2015) como autores referenciados na educação física uruguaia os brasileiros Valter Bracht (anteriormente mencionado) e Carmem Lúcia Soares $^{23}$ (SOARES, 1998), embora não sejam feitas menções a obras da pesquisadora. P1UY (2015a) lembra interlocutores de renome no campo da sociologia, a exemplo de Norbert Elias, Raymond Williams e Pierre Bourdieu. P3UY (2015) menciona os nomes de Le Breton, Julia Varela e Fernando Álvarez-Uría. P2UY (2015, tradução nossa), por sua vez,

23 Embora P3UY (2015) tenha citado o nome de Carmem Lúcia Soares como uma das autoras trabalhadas na educação física no Uruguai, não houve menção a nenhuma obra em particular. Apesar disso, encontramos em uma produção teórica de P3UY (SERÉ QUINTERO, 2007) referência à obra “Educação Física: raízes europeias e Brasil" (SOARES, 2001). 
afirma que "as referências baseiam-se, grande parte, em autores espanhóis", especialmente aqueles que influenciaram os processos de reforma educativa no país, nos anos de 1990, a exemplo de Arnold (1991), que discute educação física, movimento e currículo; Decreto Escola, documento do Ministério da Educação e Ciência (ESPAÑA, 1994) ou Haro e Alvárez (1997) que tratam a educação física em Barcelona, contando ainda com aporte de autores argentinos para tratar da cultura na educação física escolar, quais sejam: Giraldes (1994), que aborda a didática da cultura do corpo ou González de Álvarez e Rada de Rey (1998), que se dedicam à didática da educação física infantil. Mesmo com as contribuições teóricas, o enfoque da educação física seria, ainda, “[...] tecnocrático e os autores trabalhados fundamentalmente baseiam-se em conceitos de atividade e exercício físico" (P2UY (2015, tradução nossa). O Quadro 1 sintetiza as questões levantadas, ilustrando as considerações dos docentes acerca do tema cultura na produção do conhecimento em educação física no Uruguai.

A educação física encontra-se, segundo os participantes da pesquisa, orientada pelo conceito de cultura física fundado em base higienista e eugenista, embora sejam percebidos avanços a partir do diálogo com autores de outros países que fazem interlocução com as ciências humanas e sociais. Os avanços em termos de pesquisa na educação física, na realidade local dos docentes entrevistados, dão-se por meio do acesso a pesquisadores e produções advindos de outras realidades (a exemplo da brasileira, da espanhola, da argentina, da francesa, da inglesa, entre outras) e se constituem no contexto universitário, notadamente, na UdelaR, como loco de pesquisa/produção de conhecimento e como espaço de formação de pessoas. O conceito de cultura integra a realidade da educação física escolar e da produção de conhecimento no Uruguai sob o viés da cultura física, o que faz com que ele seja desprovido de seu potencial crítico para a percepção de um ser humano para além de sua forma "naturalizada" e de seu corpo mecânico. Contudo, avanços são percebidos no intuito de qualificar as ações na área rumo a uma educação física que seja promissora no país. As reflexões acerca do tema da qualidade na educação/educação física complementam essa percepção. 
Quadro 1 - Síntese das respostas dos pesquisadores relacionadas ao tema cultura na educação física.

\begin{tabular}{|c|c|c|c|}
\hline \multirow[b]{2}{*}{ Problemáticas } & \multicolumn{3}{|c|}{ Pesquisadores } \\
\hline & $\begin{array}{l}\text { Rodríguez Giménez } \\
\text { P1UY (2015a) }\end{array}$ & $\begin{array}{l}\text { Dogliotti } \\
\text { P2UY (2015) }\end{array}$ & $\begin{array}{l}\text { Seré Quintero } \\
\text { P1UY (2015a) }\end{array}$ \\
\hline $\begin{array}{l}\text { Conceito de } \\
\text { cultura na } \\
\text { produção de } \\
\text { conhecimento em } \\
\text { Educação Física no } \\
\text { Uruguai }\end{array}$ & $\begin{array}{l}\text { - Forma parte das } \\
\text { discussões no } \\
\text { campo. } \\
\text { - Associado à ideia } \\
\text { de "cultura física". } \\
\text { - Analisado } \\
\text { criticamente a } \\
\text { partir da relação } \\
\text { natureza-cultura. }\end{array}$ & $\begin{array}{l}\text { •É escasso. } \\
\text { - Discutido no GPEPI/ } \\
\text { ISEF. }\end{array}$ & $\begin{array}{l}\text { •É recente. } \\
\text { •Associado a noções } \\
\text { de “cultura física" ou } \\
\text { "cultura corporal”. } \\
\text { •Vínculo com outras } \\
\text { esferas do saber } \\
\text { (ciências humanas e } \\
\text { sociais). } \\
\text { - Mencionado, mas } \\
\text { não aprofundado. }\end{array}$ \\
\hline $\begin{array}{l}\text { Sobre os conceitos } \\
\text { cultura física, } \\
\text { cultura corporal } \\
\text { e cultura do } \\
\text { movimento }\end{array}$ & $\begin{array}{l}\text { - Não existe } \\
\text { conceito } \\
\text { predominante. } \\
\text {-O conceito tratado } \\
\text { pelo Estado é o } \\
\text { conceito de cultura } \\
\text { física. }\end{array}$ & $\begin{array}{l}\text {-Cultura física } \\
\text { predominante desde } \\
1906 . \\
\text {-Cultura corporal } \\
\text { e cultura do } \\
\text { movimento são } \\
\text { conceitos advindos } \\
\text { de referenciais } \\
\text { brasileiros. } \\
\text {-Conceito alternativo } \\
\text {-práticas corporais } \\
\text { (ciências humanas e } \\
\text { sociais). }\end{array}$ & $\begin{array}{l}\text { - Cultura física e } \\
\text { cultura corporal são } \\
\text { predominantes. } \\
\text { - Conceito de cultura } \\
\text { física pautado no } \\
\text { caráter higienista e } \\
\text { eugenista. }\end{array}$ \\
\hline $\begin{array}{l}\text { O trato com o } \\
\text { tema cultura nas } \\
\text { aulas de Educação } \\
\text { física escolar }\end{array}$ & $\begin{array}{l}\text { - Crítica cultural } \\
\text { parte da nova } \\
\text { geração de } \\
\text { professores. } \\
\text { - Quebra da } \\
\text { hegemonia } \\
\text { biomédica. } \\
\text { - Futebol tratado } \\
\text { como fenômeno } \\
\text { cultural. }\end{array}$ & $\begin{array}{l}\text { •Compreensão das } \\
\text { dinâmicas instituídas } \\
\text { nas escolas e seu } \\
\text { lugar na produção } \\
\text { e reprodução } \\
\text { social por meio do } \\
\text { acompanhamento de } \\
\text { estágios e práticas de } \\
\text { ensino. }\end{array}$ & $\begin{array}{l}\text { - As discussões dos } \\
\text { temas da cultura } \\
\text { corporal no ISEF se } \\
\text { diferem em como isso } \\
\text { se traduz em uma } \\
\text { aula de educação } \\
\text { física. } \\
\text { •O tema começa a } \\
\text { ser desenvolvido, } \\
\text { mas não como algo } \\
\text { hegemônico e sim } \\
\text { alternativo. }\end{array}$ \\
\hline $\begin{array}{l}\text { Marcos teóricos } \\
\text { sobre cultura na } \\
\text { educação física } \\
\text { escolar }\end{array}$ & $\begin{array}{l}\text {-Autores do próprio } \\
\text { ISEF/UdelaR. } \\
\text { - Valter Bracht. } \\
\text { - Norbert Elias, } \\
\text { Raymond } \\
\text { Williams, Pierre } \\
\text { Bourdieu, entre } \\
\text { outros. }\end{array}$ & $\begin{array}{l}\text {-Autores espanhóis, } \\
\text { argentinos e outros. }\end{array}$ & $\begin{array}{l}\text { - Carmen Lúcia Soares, } \\
\text { Valter Bracht. } \\
\text { - David Le Breton, Julia } \\
\text { Varela e Fernando } \\
\text { Alvarez-Uria. }\end{array}$ \\
\hline
\end{tabular}

Fonte: Elaborado pelos autores a partir das informações fornecidas por P1UY (2015a), P2UY (2015) e P3UY (2015), (tradução nossa). 


\section{REFLEXÕES ACERCA DA QUALIDADE NA EDUCAÇÃO/EDUCAÇÃO FíSICA URUGUAIA}

Ao trazermos questões relativas à qualidade na educação/educação física partimos do entendimento da qualidade não como ente metafísico a ser reverenciado, mas como elemento investigativo que vem a somar ao debate interventor acerca das condições necessárias para que os sujeitos sejam valorizados em sua formação humanística e em seu contexto social específico. Embora haja aspectos orientadores em nível internacional (CEPAL, 2000; UNESCO, 2002; 2003; BANCO MUNDIAL, 1999; 2002) em relação ao que seja "qualidade" não podemos tomá-los como modelos universais, mas como orientadores para o estabelecimento de um consenso mínimo a ser observado, passíveis de críticas, haja vista as particularidades daqueles que compõem distintas realidades, em diferentes países e comunidades, e que precisam ser observadas e consideradas naquilo que entendemos por educação. Nessa direção, como complementam Dourado e Oliveira (2009, p. 202), as finalidades educativas dependem do "alcance do que se almeja como qualidade da educação", vinculadas "[...] aos diferentes espaços, atores e processos formativos, em seus diferentes níveis, ciclos e modalidades educativas, bem como à trajetória histórico-cultural e ao projeto de nação [...]", haja vista que as diretrizes e bases do sistema educacional indicam o campo jurídico normativo em que "a educação se efetiva ou não como direito social".

Com base nos autores supracitados, buscamos tratar o tema qualidade na educação/ educação física no Uruguai, levando em consideração as especificidades próprias de uma dada cultura em relação ao tema, cuja interlocução contribui para pensarmos essa problemática na nossa própria realidade. Daí o questionamento feito aos docentes ter envolvido as seguintes questões: a) para você, o que é qualidade na educação?; b) pode-se afirmar que existe qualidade na educação física em seu país?; c) o tema qualidade na educação física é debatido em seu país?; se sim, como esse debate acontece?

A partir das respostas dos professores, foi possível observar que o entendimento do que seja qualidade na educação/educação física não se define de maneira simples, necessitando uma análise que considere fatores diversos. Apesar disso, os participantes incursionam por questões que tocam diretamente sua realidade cultural. Para P1UY (2015a), essa não é uma questão fácil de responder devido à incorporação do discurso neoliberal na educação, mas entende por educação de qualidade "aquela que privilegia o saber, que consegue colocar à disposição das novas gerações o que se tornou mais elevado na cultura universal" (tradução nossa).

P2UY (2015, tradução nossa) não acredita na essencialidade do conceito e entende que ele compreende "[...] múltiplos significados, de acordo com o contexto histórico, social, cultural e a perspectiva teórica desde onde se inicia". Para P3UY (2015, tradução nossa), qualidade na educação "[...] deveria compreender a centralidade do conhecimento posto em jogo no ato educativo, o tratamento crítico do ensino e a atualização quanto ao saber", sendo importante o vínculo da educação com a "produção de conhecimento e a formação em nível de pós-graduação dos docentes que ali trabalham".

Acerca da existência ou não da qualidade na educação/educação física do Uruguai, P1UY (2015a, tradução nossa) afirma que existem sérias tentativas para que a educação 
física no Uruguai "[...] esteja à altura de um saber, e não simplesmente de uma atividade". P2UY (2015) entende não haver qualidade na educação física em seu país e P3UY (2015, tradução nossa) afirma que é difícil responder a esse questionamento devido ao vasto campo da educação física, bem como à "multiplicidade de espaços e atividades que esta abarca". Essa última docente prefere não afirmar a existência ou a inexistência de qualidade na educação física, porque, segundo ela, a avaliação de qualidade depende dos interesses políticos atrelados a esse campo, o que vai ao encontro das considerações trazidas por Dourado e Oliveira (2009, p. 204) no tocante às políticas educacionais. Os referidos autores afirmam que é necessário identificar "[...] quais são os compromissos assumidos pelos diferentes países na área da educação, como tais compromissos se configuram em políticas, programas e ações educacionais e como eles se materializam no cotidiano escolar". Nessa direção, a qualidade na educação física passa a estar vinculada, segundo a docente, aos interesses que acometem os diferentes sujeitos num dado contexto social.

Com relação aos interesses que permeiam a qualidade na educação física, citados por P3UY (2015), alguns questionamentos orientam reflexões que podem se desdobrar futuramente, quais sejam: a) os conhecimentos presentes na educação física do ISEF/ UdelaR contribuem para se pensar na identidade da educação física no país?; b) esses conhecimentos interessam a quem (aos âmbitos acadêmico, político ou outros)? Tais reflexões não são facilmente "medidas", conforme afirma P3UY (2015), sendo respondidas, apenas, com o tempo e diante de muitos estudos e discussões epistemológicas geradoras de debates necessários à área, ainda que incipientes, haja vista a formação acadêmica em educação física na UdelaR ser recente, assim como suas linhas de investigação, acrescenta P1UY (2015a) (2015).

Ainda sobre essa questão, P2UY (2015, tradução nossa) aponta que o debate principal ocorre mais em "nível de qualidade do esporte do que de educação física", uma vez que, segundo a pesquisadora, "uns entendem por qualidade: muita prática de atividade física e competitiva" e "outros se opõem a este modelo", entendendo "que a qualidade está nas variadas experiências corporais" e que o esporte não "é o único a impulsionar". Para P3UY (2015), a noção de qualidade "tem permanecida bastante alheia ao campo da educação física", porém, debates têm ocorrido acerca do caráter da educação física, possibilitando a identificação de duas gerações de professores: os mais velhos, cuja didática predomina o "activismo ${ }^{24 "}$ (P1UY, 2015b) e os mais novos, cuja didática permite ensinar as atividades e fazer as devidas reflexões, levando em consideração os contextos social, cultural e político.

Nota-se que os entendimentos acerca da existência ou não de qualidade na educação física, na realidade dos pesquisadores entrevistados, perpassam conflitos de identidade no campo. Rozengardt (2004) afirma que a educação física pode modificar-se em função de sua identidade e o meio social ao qual a legitima, mas, para que haja essa modificação, três frentes simultâneas devem ser consideradas: os discursos, as práticas e as 
representações. O autor sugere que os problemas da constituição do sujeito pedagógico, a construção do saber e sua relação com objeto marcam uma dimensão inevitável a ser revisada criticamente com as propostas do campo. O Quadro 2 apresenta a síntese das questões tratadas nesse eixo temático.

Quadro 2 - Síntese das respostas dos pesquisadores relacionadas ao tema qualidade na educação/educação física no Uruguai

\begin{tabular}{|c|c|c|c|}
\hline \multirow[b]{2}{*}{ Problemáticas } & \multicolumn{3}{|c|}{ Pesquisadores } \\
\hline & $\begin{array}{l}\text { Rodríguez Giménez } \\
\text { P1UY (2015a) }\end{array}$ & $\begin{array}{c}\text { Dogliotti } \\
\text { P2UY (2015) }\end{array}$ & $\begin{array}{l}\text { Seré Quintero } \\
\text { P3UY (2015) }\end{array}$ \\
\hline $\begin{array}{l}\text { Qualidade na } \\
\text { educação }\end{array}$ & $\begin{array}{l}\text {-Aquela que } \\
\text { privilegia o saber } \\
\text { e que preza pelo } \\
\text { alcance da cultura } \\
\text { universal. }\end{array}$ & $\begin{array}{l}\text { - Conceito de } \\
\text { múltiplos } \\
\text { significados. }\end{array}$ & $\begin{array}{l}\text { - Centralidade do } \\
\text { conhecimento posto } \\
\text { em jogo no ato } \\
\text { educativo. } \\
\text { - Tratamento crítico } \\
\text { do ensino. } \\
\text { - Atualização do } \\
\text { saber. }\end{array}$ \\
\hline $\begin{array}{l}\text { Qualidade na } \\
\text { educação física }\end{array}$ & $\begin{array}{l}\text { • Existem sérias } \\
\text { tentativas por parte } \\
\text { dos professores } \\
\text { uruguaios para que } \\
\text { a educação física } \\
\text { esteja à altura de } \\
\text { um saber e não } \\
\text { meramente tratada } \\
\text { como atividade. }\end{array}$ & $\begin{array}{l}\text { - Não entende haver } \\
\text { qualidade na } \\
\text { educação física no } \\
\text { Uruguai devido a } \\
\text { vários fatores. }\end{array}$ & $\begin{array}{l}\text { •Não consegue } \\
\text { afirmar se existe } \\
\text { qualidade na } \\
\text { educação física } \\
\text { devido "aos } \\
\text { interesses aos quais } \\
\text { esta se aproxima". }\end{array}$ \\
\hline $\begin{array}{c}\text { Debate acerca } \\
\text { da qualidade na } \\
\text { educação física }\end{array}$ & $\begin{array}{l}\text {-Debate pouco } \\
\text { desenvolvido no } \\
\text { ensino superior. }\end{array}$ & $\begin{array}{l}\text {-O debate ocorre } \\
\text { mais relacionado } \\
\text { ao esporte do que } \\
\text { propriamente à } \\
\text { educação física. }\end{array}$ & $\begin{array}{l}\text { •A noção de } \\
\text { qualidade está } \\
\text { alheia ao campo da } \\
\text { educação física. }\end{array}$ \\
\hline
\end{tabular}

Fonte: Elaborado pelos autores a partir das informações fornecidas por P1UY (2015a), P2UY (2015) e P3UY (2015), (tradução nossa).

Com base nos apontamentos realizados pelos participantes da pesquisa, nota-se a dificuldade em se pensar em qualidade na educação física pelo fato do próprio entendimento de qualidade estar à mercê dos interesses políticos, econômicos e sociais de quem pensa efetivamente essa qualidade. Em complemento, os colaboradores falam dessa dificuldade de visualização da qualidade pelo fato da educação física ser vista como "atividade" e ser tema pouco debatido na realidade uruguaia, o que contribui para refletirmos acerca dos cuidados necessários à problematização do tema. Tais apontamentos nos levam a lembrar que, ao elegermos o tema da qualidade na educação/educação física como campo investigativo, não desconsideramos as nuanças assumidas em realidades distintas da brasileira, em suas aproximações e distanciamentos, embora o tenhamos feito pensando na qualidade 
a partir das condições que propiciem o "melhoramento" da educação física em termos de formação humanística, com capacidade de potencializar o sujeito na construção de sua autonomia e emancipação, com conhecimento de seu corpo e da importância de sua experiência formativa por meio das distintas práticas corporais.

\section{CONCLUSÃO}

Ao discorrermos acerca da cultura e da qualidade na educação/educação física no contexto uruguaio, notadamente a partir de dados obtidos por meio da colaboração de pesquisadores ligados à Universidad de la República, foi possível satisfazer algumas das necessidades epistêmicas no tocante à percepção de como uma dada área organiza seu campo. De modo especial, nosso interesse investigativo recaía em perceber se a cultura era tematizada na educação física e de que modo essa relação ocorria. Disso decorre o entendimento de que o tema da cultura ainda é secundário em relação às tradicionais abordagens da educação física, tais como os conteúdos que envolvem a competição, o desporto e os aspectos anatomofisiológicos do corpo. Predomina, naquela realidade, como informam os pesquisadores, a utilização do termo cultura associado ao físico, culminando no conceito de cultura física vinculado a uma perspectiva fragmentária de ser humano com foco na fisicalidade.

Contudo, para além dos conteúdos que se amparam na tradição de um formato de educação física, avanços podem ser percebidos na ruptura com essa perspectiva, sobretudo pela ampliação do quadro de professores uruguaios que transcendem a leitura ingênua do campo, focada na percepção dicotômica do sujeito. Para os docentes participantes da pesquisa, a tematização da cultura dá-se pela relação com os estudos do corpo para além dos aspectos orgânicos que propiciam à cultura o espaço profícuo para se desenvolver na educação física uruguaia, embora ainda essa seja uma realidade em construção, motivada por influências de pesquisadores de outros países, a exemplo do conceito de cultura corporal desenvolvido na realidade brasileira, bem como do conceito de práticas corporais, os quais são entendidos como caminhos alternativos e não hegemônicos.

Notamos que o conceito acerca da temática qualidade na educação envolve vários fatores e que não há consenso entre os docentes quando questionados em relação à possibilidade de ter ou não qualidade na educação física no Uruguai, sobretudo porque essa qualidade é movida por interesses (qualidade do quê?, para quem?; pensada por quem?), algo que eles fizeram questão de reforçar. A qualidade nos sistemas educacionais - do escolar ao ensino superior - depende de vários fatores que não são facilmente medidos e requerem investimentos por parte de seus governantes para que o significado da qualidade, no melhor sentido do termo, seja de fato oportunizado. Daí o tema da qualidade na educação física, segundo os pesquisadores, ter suas carências, as quais estão relacionadas à própria construção identitária limitante da educação física, associada tradicionalmente a finalidades esportivas e de "mera atividade", o que faz com que esse debate seja esvaziado ou tenha pouca ressonância. 
No diálogo estabelecido com os pesquisadores participantes da pesquisa, entendemos que a qualidade tende a ser potencializada quando a educação física passar a ser olhada pela dimensão cultural, valorizada em sua diversidade de expressões, para além de uma perspectiva naturalizada do ser humano. É o que, a nosso ver, começa a ocorrer na realidade investigada a partir dos desdobramentos investigativos advindos do envolvimento de professores/pesquisadores da Universidad de la República com uma educação física que pense o ser humano para além de uma perspectiva centrada no "físico", amparada por referenciais das ciências humanas e sociais que possam contribuir para ampliar o alcance interpretativo da área. Nesses caminhos, a educação física, na perspectiva dos docentes uruguaios, dialoga com a nossa realidade, haja vista que produções teóricas de pesquisadores brasileiros chegam até o contexto uruguaio como aportes para se pensar a construção de uma educação física humanística e interventora na realidade social, motivando, inclusive, a complementação da formação em nível de pós-graduação25. Percebemos nesse conjunto de fatos valiosa contribuição para se pensar em uma educação física orientada por uma racionalidade ético-estética que tenha sentido como campo de educação corporal a agregar a outras perspectivas epistemológicas e de intervenção no contexto latino-americano.

\section{REFERÊNCIAS}

ARNOLD, P.J. Educación Física, movimiento y curriculum. Madrid: Morata, 1991.

BANCO MUNDIAL. Brasil: justo, competitivo, sustentável - contribuições para debate. Washington, D.C., 2002. Disponível em: < http://www.bancomundial.org >. Acesso em: 08 set. 2016.

. Estratégia do Banco Mundial para a Educação na América Latina e no Caribe, 1999. Disponível em: < http://www.bancomundial.org >. Acesso em: 08 set. 2016.

BRACHT, Valter. Educação física e aprendizagem social. Porto Alegre: Magister, 1992.

CEPAL. Cinquenta anos de pensamento na Cepal. Organização, Ricardo Bielschowsky; tradução de Veta Ribeiro. Rio de Janeiro: Record, 2000.

DAOLIO, J. Educação física e o conceito de cultura. Campinas, SP: Autores Associados, 2004.

DEMARCHI, M, RODRIGUEZ, H. José Pedro Varela. Recife: Fundação Joaquim Nabuco, 2010. Disponível em: <http://www.dominiopublico.gov.br/download/texto/me4684. pdf >. Acesso em: 14 set. 2014.

DOGLIOTTI, P. La formación de maestros de educación física en el Uruguay (19211930): Julio J. Rodríguez. História e Educação [Online]. Porto Alegre v. 17, n. 41, set./dez., p. 139-158, 2013a. Disponível em: < http://www.redalyc.org/articulo. oa? $\mathrm{id}=321628477009>$. Acesso em: 09 set. 2016 .

25 Aqui, referimo-nos, especificamente, à formação em nível de pós-graduação stricto-sensu realizada no Brasil por dois dos pesquisadores participantes da investigação. 
. Alejandro Lamas: "cultura física" en el primer plan de educación física escolar en Uruguay. Movimento (Porto Alegre), v. 19, n. 1, p. 203-220, 2013b. Disponível em: < seer.ufrgs.br/Movimento/article/download/33961/24410>. Acesso em: 09 set. 2016.

. Una mirada sobre los discursos que atraviesan a las políticas de educación física escolar en el Uruguay (2006 - 2011). Anais. VI Congresso Sulbrasileiro de Ciências do Esporte, 2012a. Disponível em: < http://congressos.cbce.org.br/index.php/6csbce/ sul2012/rt/suppFileMetadata/4030/2133/399 > . Acesso em: 06 set. 2015.

. Educación del cuerpo, higiene y gimnástica en la conformación de la educación física escolar en el Uruguay (1874-1923). Anuario de la Sociedad Argentina de Historia de la Educación. v. 13, n. 2, 2012b, Argentina. Disponível em: < http://ppct.caicyt.gov. ar/index.php/anuario/article/view/2487/2339> . Acesso em: 15 nov. 2014.

. Cuerpo y curriculum: discursividades en torno a la formación de docentes de educación física en Uruguay (1874-1948). Montevideo: FHCE, 2012c. Dissertação de Mestrado (Mestrado em Ensino Universitário). Área Social. Comisión Sectorial de Enseñanza. Universidad de la República, Uruguay.

. Lo político y las políticas educativas: el cambio curricular en la reforma educativa uruguaya (1995-2000). Políticas Públicas, Campinas, v. 2, n. 2, dez., p.18-33, 2009. Disponível em: < http://seer.ufrgs.br/Poled/article/view/18376>. Acesso em: 09 set. 2016.

DOURADO, L.F, OLIVEIRA, J.F. A qualidade da educação: perspectivas e desafios. Caderno Cedes, Campinas, v. 29, n. 78, p. 201-215, maio/ago. 2009. Disponível em: < http://www. scielo.br/pdf/ccedes/v29n78/v29n78a04.pdf > . Acesso em: 14 set. 2014.

ESPAÑA. Consejería de Educación y Ciencia, Decreto de Bachillerato. Área de Educación Física. p. 8760. Sevilla: BOJA n. 115. España, 1994. Disponível em: < http://www. gobiernodecanarias.org/educacion/web/bachillerato/informacion/ordenacion_curriculo_ competencias/ordenacion-curriculos-lomce.html >. Acesso em: 09 set. 2016.

GIRALDES, M. Didáctica de una cultura de lo corporal. Buenos Aires: Gráficas, Guadalupe, 1994. GOERGEN, P. Educação superior na perspectiva do sistema e do plano nacional de educação. Educação e Sociedade, Campinas, v. 31, n. 112, jul./set., p. 895-917, 2010. Disponível em: < http://www.scielo.br/pdf/es/v31n112/13.pdf>. Acesso em: 13 set. 2013. GONZÁLEZ DE ÁLVAREZ, M. L.; RADA DE REY, B. A. La Educación física infantil y su didáctica. Buenos Aires: A-Z Editora, 1998.

HARO, M. de; ALVAREZ, J. L. Educación Física. Barcelona. Paidotribo, 1997.

LARA, L.M. Os pecados capitais da educação física brasileira e suas demarcações constitutivas.

Educação e Fronteiras, v. 6, p. 94-110, 2016. Disponível em: < http://ojs.ufgd.edu.br/ojs/index.ph p?journal $=$ educacao\&page $=$ article \&op $=$ view \&path $\% 5 B \% 5 D=5942 \&$ path $\% 5 B \% 5 D=3104>$. Acesso em: 21 fev. 2017.

, L.M. Identidades e práticas corporais na produção de conhecimento em educação física. In: IV Engrupe Dança - Encontro Nacional dos Grupos de Pesquisa em Dança, 2013, Recife. Anais ... IV ENGRUPE - Encontro Nacional dos Grupos de Pesquisa em Dança. Recife: EDUFPE, 2013. p. 140-153. Disponível em: < http://engrupe.cooperacdanca.org/index.php/engrupe/engrupe-n4/ paper/download/107/106>. Acesso em: 21 fev. 2017. 
LOPES, B. R. A cultura na produção de conhecimento da educação física brasileira: centralidade ou periferia? Dissertação (Mestrado em Educação física). Programa de Pós-Graduação Associado em Educação física UEM-UEL. Maringá, 2013.

P1UY (2015a). Participação de Raumar Rodríguez Giménez na pesquisa Panorama da educação física escolar latino-americana: dimensões da cultura e qualidade na educação. Questionário. Universidad de la República. Montevideo, Uruguai, $1^{\circ}$ abr. 2015a.

P1UY (2015b). Participação de Raumar Rodríguez Giménez na Reunião Institucional realizada pelo Grupo de Pesquisa Corpo, Cultura e Ludicidade, realizada no VI Congresso Internacional de Pedagogia do Esporte-CIPE, Universidade Estadual de Maringá, Maringá, 27 ago. 2015b.

P2UY (2015). Participação de Paola Dogliotti na pesquisa Panorama da educação física escolar latino-americana: dimensões da cultura e qualidade na educação. Questionário. Universidad de la República. Montevideo, Uruguai, 20 abr. 2015.

P3UY (2015). Participação de Cecília Seré Quintero na pesquisa Panorama da educação física escolar latino-americana: dimensões da cultura e qualidade na educação. Questionário. Universidad de la República. Montevideo, Uruguai, 10 jul. 2015.

RODRÍGUEZ C.C.A; RUEGGER O.M.C; TORRÓN P.A. Política, escuela y cuerpo: los sentidos de la Educación Física "obligatoria" en la escuela uruguaya. Anais. $8^{\circ}$ Congreso Argentino y $3^{\circ}$ Latinoamericano de Educación Física y Ciencias. La Plata, 2009. Disponível em: < http://congresoeducacionfisica.fahce.unlp.edu.ar/descargables/ politica-escuela-y-cuerpo-los-sentidos-de-la-educacion-fisica-obligatoria-en-la-escuelauruguaya $>$. Acesso em: 06 out. 2014.

RODRÍGUEZ GIMÉNEZ, R. Educación del cuerpo y políticas educativas: de la formación superior al patio escolar. Revista Iberoamericana de Educacion (Impr.), v.62, p. 107 - 117, 2013. Disponível em: <http://www.rieoei.org/rie_contenedor. php?numero $=$ rie62 $>$. Acesso em: 14 set. 2014.

. Notas para una investigación sobre pedagogía y biopolítica. Educación Física y Deporte, v.29, n. 2, 2010, p. 215-223. Disponível em: < http://aprendeenlinea.udea. edu.co/revistas/index.php/educacionfisicaydeporte/article/view/8497/8027 > . Acesso em: 21 fev. 2017.

. El espectáculo del cuerpo militarizado. Educar em Revista, v. 33, jan. 2009, p.129-140.

. Breve reflexión sobre la experiencia y el cuerpo. Educação Temática Digital, v.8, 2007, p.31-47. Disponível em: < http://www.scielo.br/scielo.php?pid=S010440602009000100009\&script $=$ sci_abstract\&tlng =es $>$. Acesso em: 21 fev. 2017.

ROZENGARDT, R. El sujeto pedagógico de la Educación Física: teoría, práctica y crítica. Educación Física y Deporte. Antioquía, v. 23, n. 1, p. 45-55, 2004. Disponível em: < http://aprendeenlinea.udea.edu.co/revistas/index.php/educacionfisicaydeporte/ article/view/2559>. Acesso em: 09 set. 2016.

SERÉ QUINTERO, C. La enseñanza y la educación del cuerpo infantil: cuando el lenguaje intercede con "lo vivo". Educación Física y Ciencia, v. 13, 2011, p.35-50. Disponível em: < http://www.efyc.fahce.unlp.edu.ar/article/view/EFyCv13a03 > . Acesso em: 21 fev. 2017. 
, Reflexión sobre la construcción del cuerpo al interior del espacio escolar. ISEF Digital, v. 1, p. 1-12, 2007. Disponível em: < http://issuu.com/isef/docs/undecima edicion >. Acesso em: 21 fev. 2017.

SERÉ QUINTERO, C.; FERNÁNDEZ VAZ, A. Montevideo, tu casa": elementos para una lectura del cuerpo en el espacio público moderno. Lúdica Pedagógica, v. 1, n. 21, jan. 2015, p.33-42. Disponível em: < http://revistas.pedagogica.edu.co/index.php/LP/ article/view/2710/2881 >. Acesso em: 21 fev. 2017.

SILVA, A.M.; BEDOYA, V.A.M. (Orgs.). Formação profissional em Educação Física na América Latina: encontros, diversidades e desafios. Jundiaí: Paço Editorial, 2015.

SILVA, S.S.; TORTOLA, E.R.C.; MONTENEGRO, J.; LARA, L. Dimensões da educação física escolar colombiana e incursões pela tematização da cultura e qualidade na educação. Cuerpo, Cultura y Movimento, v. 5, n.1, jan./jun. 2015, p. 35-56.

SOARES, C.L. Educação física: raízes europeias e Brasil. 2. ed. Campinas, SP: Autores Associados, 2001.

UNESCO. Laboratório Latinoamericano de Evaluación de la Calidad de la Educación. Estudio cualitativo de escuelas con resultados destacables en siete países latinoamericanos. Santiago de Chile, set. 2002. Disponível em: < http://www.prie.cl. > Acesso em: 08 set. 2016.

UNESCO. Cumbre de las Américas. Alcanzando las metas educativas: Informe Regional. Proyecto Regional de Indicadores Educativos, Santiago de Chile, ago. 2003. Disponível em: <http://www.prie.cl>. Acesso em: 08 set. 2016.

URUGUAY. Panorama de la educación en el Uruguay: una decada de transformaciones:1994-2004. Montevideo: Programa de Evaluación de la Gestión, 2005. Disponível em: <www.anep.edu.uy/.../117-publicaciones-division-de-investigaciony-estadistica-educat $>$. Acesso em: 15 ago. 2016.

URUGUAY. Ley 18.437. Ley general de educación. Ministerio de Educación. Montevidéo, UY, 2009. Disponível em: < http://www2.ohchr.org/english/bodies/cat/docs/AnexoXIV Ley18437.pdf > . Acesso em: 28 maio 2015.

URUGUAY. Proyecto de Obligatoriedad de la Educación Física Escolar. Ley de obligatoriedad de la Educación Física Escolar, nº. 18213, dez. 2007. Disponível em: $<$ docs.uruguay.justia.com/.../leyes/ley-18213-dec-5-2007.pdf>. Acesso em: 20 abr. 2016

Recebido em: setembro/2016

Aprovado em: maio/2017 